\title{
Effect of Anti-TNF-a on the Development of Offspring and Pregnancy Loss During Pregnancy in Rats
}

\author{
Ayse Er', Ibrahim Aydin² \& Burak Dik
}

\begin{abstract}
Background: Etanercept binds soluble tumor necrosis factor-alpha (TNF- $\alpha$ ) and is classified as pregnancy risk category B. Increase in TNF- $\alpha$ level causes preterm labour or miscarriage. Lipopolysaccharides trigger preterm birth and abortion via producing of pro-inflammatory cytokines. Cytokines are divided into two groups as pro-inflammatory and anti-inflammatory. TNF- $\alpha$ is a pro-inflammatory cytokine, whereas interleukin (IL)-10 is an anti-inflammatory cytokine. IL-10 predominant in normal pregnancy while TNF- $\alpha$ characterize in abortion and recurrent abortion. The aim of this study was to determine the effect of etanercept on the development of offspring and lipopolysaccharide-induced pregnancy loss.

Materials, Methods \& Results: Twenty-eight female and 7 male Wistar rats (5-6 months old) were used in this study. The rats were fed a standard pelleted diet and tap water ad libitum. After female rats were caged with males for 1 day, the presence of a vaginal plug was designated as day 0 of pregnancy. Twenty-eight pregnant Wistar rats were divided into 4 equal groups, as follows: control ( $0.3 \mathrm{~mL}$ of Normal Saline Solution intravenously on day 10 of pregnancy); etanercept ( 0.8 $\mathrm{mg} \mathrm{kg}^{-1} /$ day intraperitoneally on days 9 and 10 of pregnancy); lipopolysaccharide (160 $\mathrm{g} \mathrm{kg} \mathrm{k}^{-1}$ intravenously on day 10 of pregnancy); and etanercept + lipopolysaccharide. Blood samples were obtained from the tail vein on day 10 of pregnancy ( $3 \mathrm{~h}$ after lipopolysaccharide administration). All animals were followed during pregnancy. Pregnancy rates and offspring characteristics were determined. TNF- $\alpha$ and IL-10 levels were measured using an ELISA reader. Etanercept alone did not have any negative effects, and etanercept did not prevent $(P<0.05)$ lipopolysaccharide-induced pregnancy loss. Higher TNF- $\alpha$ and IL-10 levels were measured $(P<0.05)$ in the etanercept + lipopolysaccharide group compared to other groups. Discussion: It is well known that use of etanercept does not increase pregnacy loss. In this study, higher pregnancy rates were determined in the control and etanercept groups than the lipopolysaccharide and etanercept + lipopolysaccharide groups. The proportion of fetal deaths in lipopolysaccharide administered pregnant subjects was decreased by the use of anti-TNF- $\alpha$ agents. While the concentrations of TNF- $\alpha$ are low in the onset of pregnancy period, the concentrations of TNF- $\alpha$ increases a peak level during the onset of labour. Embryonic resorption is affected by Th1 cytokines (TNF- $\alpha$ and lL-2) and low-dose lipopolysaccharide without any affecting mother survival, and in the early pregnancy term, the implantation area of embryo is enormously sensitive to these molecules. In the current study, etanercept increased the concentration of TNF- $\alpha$ and the concentration of IL-10 when compared to the lipopolysaccharide group. IL-10 has a protective role, while TNF- $\alpha$ is an abortive factor during pregnancy. Thus, etanercept did not prevent pregnancy loss. This finding may have reflected an insufficient dose of etanercept. Adverse effects did not occur in the offspring of the etanercept or control groups, and there was no difference between the two groups statistically. Adverse pregnancy outcomes such as stillbirth, low birth weight, spontaneous abortion and herediter malformations are not associated with TNF- $\alpha$ inhibitors. In conclusion, etanercept does not pose a major teratogenic risk and has no preventive effects with respect to infection-dependent pregnancy loss.
\end{abstract}

Keywords: Anti-TNF- $\alpha$, pregnancy loss, cytokine, offspring. 


\section{INTRODUCTION}

Anti- tumor necrosis factor (anti-TNF) drugs block the functioning of TNF- $\alpha$ and are used for the treatment of immune-mediated diseases, such as psoriasis and rheumatoid arthritis $[15,21]$. TNF- $\alpha$ receptors have a pivotal role in pregnancy and the effects of TNF- $\alpha$ are neutralized by soluble forms of TNF- $\alpha$ receptors [3].

Pregnancy is a complex process and leads to activation of the maternal cellular and humoral immune system $[2,20]$. The maternal immune system identifies or refuses fetal antigens [27]. The rate of spontaneous abortion is $15-20 \%$, with unfavorable outcomes occurring during the first trimester of pregnancy [9].

Lipopolysaccharides (LPS) are derived from the cell wall of gram-negative bacteria. Because LPS triggers preterm birth and abortion via pro-inflammatory cytokines, LPS is used in experimental studies involving pregnancy $[7,17,23]$. Cytokines have an important role in the reproductive immune response and are divided into two groups (pro-inflammatory and anti-inflammatory) $[3,13]$. TNF- $\alpha$ (a pro-inflammatory cytokine) is a Thelper (Th) 1 cytokine, whereas interleukin (IL)-10 (an anti-inflammatory cytokine) is a Th2 cytokine $[3,18]$. Normal pregnancy is characterized by the predominant production of T-helper (Th) 2 cytokines, while abortion and recurrent abortion is characterized by the predominant production of Th1 cytokines [6].

Since high TNF- $\alpha$ level occurs in pregnancy loss, it has been hypothesized that etanercept, an antiTNF- $\alpha$ drug, may prevent LPS-induced pregnancy loss.

The aim of this study was to determine the effect of etanercept on LPS-induced pregnancy loss in rats and the development of offspring.

\section{MATERIALS AND METHODS}

\section{Animals}

Twenty-eight female and 7 male Wistar rats (5-6 months old) were used in this study. The rats were fed a standard pelleted diet and tap water ad libitum. The animals were bred in standard cages on a 12-h light/dark cycle at room temperature in a humiditycontrolled environment.

\section{Experimental procedure}

LPS $^{1}$ (Escherichia coli, serotype O111:B4) and etanercept $\left(\text { Enbrel }^{\circledR} \text { flk }\right)^{2}$ were diluted with pyrogenfree saline to the appropriate concentrations.
After female rats were caged with males for 1 day, the presence of a vaginal plug was designated as day 0 of pregnancy. The $10-12^{\text {th }}$ days of a rat pregnancy corresponds roughly to the first trimester of human pregnancy [24]. Pregnant rats were randomly divided into 4 groups, as follows: control group, $0.3 \mathrm{~mL}$ of normal saline solution was administered intravenously on day 10 of pregnancy $(n=7)$; etanercept group, etanercept was administered intraperitoneally at $0.8 \mathrm{mg} \mathrm{kg}^{-1}$ day on days 9 and 10 of pregnancy $(n=7)$; LPS group, LPS was administered intravenously via the tail vein at $160 \mu \mathrm{g} \mathrm{kg}^{-1}$ on day 10 of pregnancy $(n=7)$; and the etanercept + LPS group, etanercept was administered intraperitoneally at $0.8 \mathrm{mg} \mathrm{kg}^{-1}$ day on days 9 and 10 of pregnancy + LPS was administered intravenously at $160 \mu \mathrm{g} \mathrm{kg}^{-1}$ on day 10 of pregnancy $(n=7)$. Blood samples were obtained from the tail vein on day 10 of the experiment ( $3 \mathrm{~h}$ after LPS administration) and all animals were followed during pregnancy. Animals that did and did not give birth were determined. In addition, the development of offspring was assessed. At the conclusion of the study, all animals were euthanized under thiopental sodium anaesthesia (Pental ${ }^{\circledR}$ sodium $1 \mathrm{~g})^{3}$ [70 $\mathrm{mg} \mathrm{kg}^{-1}$, intraperitoneally].

\section{Measurements}

Blood samples were centrifuged and serum samples were stored at $-70^{\circ} \mathrm{C}$ until analysis. TNF- $\alpha^{4}$ (rat TNF- $\alpha$ kit, sensitivity $11 \mathrm{pg} \mathrm{mL}^{-1}$ ) and IL-10 ${ }^{4}$ (rat IL-10 kit, sensitivity $1.5 \mathrm{pg} \mathrm{mL}^{-1}$ ) levels were determined at $450 \mathrm{~nm}$ by commercial ELISA kits an with ELISA reader (MWGt Lambda Scan 200).

\section{Development of offspring}

The weight and body length of the offspring were determined with a scale and digital calipers, respectively.

\section{Statistical analysis}

The pregnancy rates of the groups were evaluated using a chi-square test. The concentrations of TNF- $\alpha$ and IL-10 and the number of offspring in each group was compared with ANOVA and a Duncan test as a post-hoc test. The weights and lengths of the offspring in the control, etanercept, and etanercept + LPS groups were evaluated by ANOVA and the Duncan test on the first day, while the same data from the control and etanercept groups were evaluated by independent $t$-tests on days 8,15 , and 22 because only 2 groups remained (SPSS 19.0). Data are expressed as the mean \pm SE. Significance was accepted at the $P<0.05$ level. 


\section{RESULTS}

The pregnancy rates of the groups are shown in Table 1, and TNF- $\alpha$ and IL-10 levels are presented in Table 2. All animals were followed during pregnancy and 22 days after birth. Etanercept did not inhibit $(P<$ $0.05)$ LPS-induced pregnancy loss, and did not exhibit adverse effects on the pregnancy rate (Table 1$)$. The TNF- $\alpha$ and IL-10 levels were higher $(P<0.05)$ in the etanercept + LPS group compared to the other groups. Although the TNF- $\alpha$ level was not determined in the etanercept and control groups, the IL-10 level was lower $(P<0.05)$ in the etanercept and control groups (Table 2). The weights and lengths of the offspring on days 1, 8, 15, and 22 are shown in Table 3. Adverse effects did not occur during the development of offspring born from rats in the etanercept alone and control groups. The number of offspring was statistically significant $(P<0.05)$ in the LPS and etanercept + LPS groups when compared to the control and etanercept groups (Figure 1).

Table 1. Pregnancy rates of groups.

\begin{tabular}{ccc}
\hline Group & Pregnant/pregnancy loss & Labour animals \\
\hline Control & $7 / 0^{\mathrm{a}}$ & 7 \\
Etanercept & $7 / 1^{\mathrm{a}}$ & 6 \\
LPS & $7 / 7^{\mathrm{b}}$ & 0 \\
Etanercept + LPS & $7 / 6^{\mathrm{b}}$ & 1 \\
\hline
\end{tabular}

LPS: lipopolysaccharide (160 $\mu \mathrm{g} \mathrm{kg}^{-1}$ intravenously, Escherichia coli 0111:B4). a,bDifferent letters in the same column are statistically significant $(P<0.05)$.

Table 2. TNF $\alpha$ and IL-10 levels of groups.

\begin{tabular}{ccc}
\hline Group & TNF $\alpha(\mathrm{pg} / \mathrm{mL})$ & IL-10 $(\mathrm{pg} / \mathrm{mL})$ \\
\hline Control & ND & $294 \pm 44.3^{\mathrm{c}}$ \\
Etanercept & ND & $206 \pm 17.4^{\mathrm{c}}$ \\
LPS & $101 \pm 17.3^{\mathrm{b}}$ & $798 \pm 115^{\mathrm{b}}$ \\
Etanercept + LPS & $1474 \pm 358^{\mathrm{a}}$ & $1817 \pm 174^{\mathrm{a}}$ \\
\hline
\end{tabular}

TNF $\alpha$ : tumor necrosis factor $\alpha$; IL-10: interleukin-10; LPS: lipopolysaccharide (160 $\mathrm{\mu g} \mathrm{kg}^{-1}$ intravenously, Escherichia coli 0111:B4). ND: not determined. ${ }^{a, b, c}$ Different letters in the same column are statistically significant $(P<0.05)$.

Table 3. Parameters of offspring in groups.

\begin{tabular}{lllllllll}
\hline & \multicolumn{2}{c}{ Day 1 } & \multicolumn{2}{c}{ Day 8} & \multicolumn{2}{c}{ Day 15 } & \multicolumn{2}{c}{ Day 22 } \\
\hline Group & Weight & Length & Weight & Length & Weight & Length & Weight & Length \\
Control & $7.39 \pm 0.10^{\mathrm{a}}$ & $51.7 \pm 0.29^{\mathrm{a}}$ & $13.3 \pm 0.21$ & $65.2 \pm 0.38^{\mathrm{a}}$ & $23.7 \pm 0.72^{\mathrm{b}}$ & $78.2 \pm 0.86$ & $34.9 \pm 1.04^{\mathrm{b}}$ & $91.0 \pm 1.14^{\mathrm{a}}$ \\
Etanercept & $7.05 \pm 0.13^{\mathrm{a}}$ & $50.8 \pm 0.28^{\mathrm{ab}}$ & $13.6 \pm 0.32$ & $63.5 \pm 0.42^{\mathrm{b}}$ & $25.5 \pm 0.49^{\mathrm{a}}$ & $76.2 \pm 0.60$ & $39.7 \pm 0.84^{\mathrm{a}}$ & $86.2 \pm 0.56^{\mathrm{b}}$ \\
Etanercept + & $5.98 \pm 0.17^{\mathrm{b}}$ & $50.1 \pm 0.45^{\mathrm{b}}$ & $\mathrm{MD}$ & $\mathrm{MD}$ & $\mathrm{MD}$ & $\mathrm{MD}$ & MD & MD \\
LPS & $\mathrm{NL}$ & $\mathrm{NL}$ & $\mathrm{NL}$ & $\mathrm{NL}$ & $\mathrm{NL}$ & $\mathrm{NL}$ & NL & NL \\
LPS & & & & & & & & \\
\hline
\end{tabular}

MD: Maternal death; NL: No labour; LPS: lipopolysaccharide (160 $\mu \mathrm{g} \mathrm{kg}^{-1}$ intravenously, Escherichia coli 0111:B4). ${ }^{\mathrm{a}, \mathrm{b}}$ Different letters in the same column are statistically significant $(P<0.05)$.

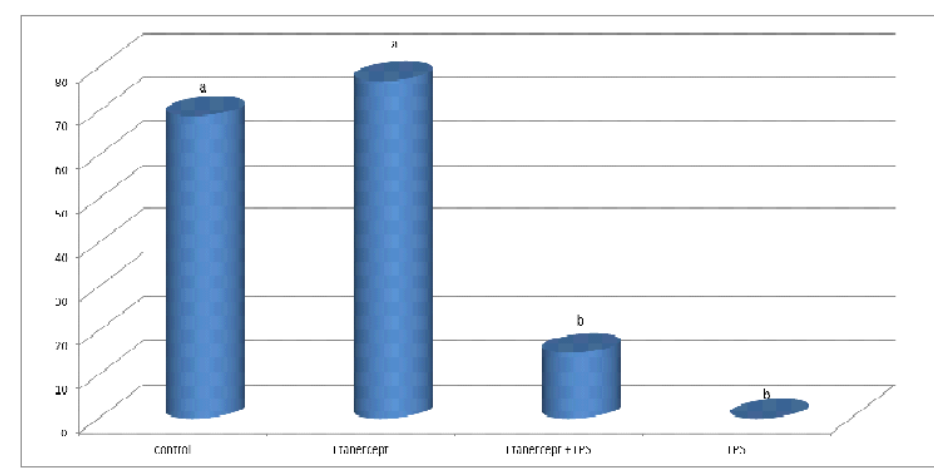

Figure 1. The number of offspring in groups. To induce pregnancy loss with LPS, $160 \mu \mathrm{g} \mathrm{kg}^{-1}$ LPS (Escherichia coli 0111:B4) was administered intravenously via the tail vein on day 10 of pregnancy in the LPS group. Etanercept was administered intraperitoneally at $0.8 \mathrm{mg} \mathrm{kg}^{-1} \mathrm{day}$ on days 9 and 10 of pregnancy in the etanercept and etanercept + LPS groups. Blood samples were obtained from the tail vein on day 10 of the experiment and all animals were followed during pregnancy. Animals that did and did not give birth were determined. a, b: Different letters are statistically significant $(P<0.05)$. 


\section{DISCUSSION}

Etanercept is a dimeric fusion protein binding that only binds soluble tumor necrosis factor-alpha (TNF- $\alpha$ ) and is classified by the Food and Drug Administration as pregnancy risk category $\mathrm{B}[8,21]$. Pregnancy outcomes, such as miscarriage, preterm labour, and pre-eclampsia, result from changes in TNF- $\alpha$ and its receptors [3]. Spontaneous abortions and pre-eclampsia are complications in pregnant women, and these complications result from a change in a Th2-biased to a Th1-biased cytokine profile in maternal serum $[3,6,28]$.

The aim of this study was to determine the effect of etanercept on cytokine levels and offspring development in LPS-induced abortion. Several inflammatory molecules play important roles in the mechanism underlying early pregnancy loss. Extreme inflammation results in unfavorable outcomes, such as spontaneous abortion and fetal resorption [1,14]. Recurrent abortion is classically defined as three or more pregnancy losses. This usually occurs before 20 weeks gestation. Recently, recurrent spontaneous miscarriage has been redefined as the spontaneous loss of two or more clinical pregnancies [12,29].

Animal models have been used to elucidate pregnancy success [16]. In the current study, etanercept alone did not have a negative effect on the pregnancy rate and did not prevent LPS-induced abortion (Table 1). It has been reported that etanercept, which is classified as pregnancy risk category $\mathrm{B}$, can be used in pregnant women; TNF- $\alpha$ antagonists have no known embryotoxic or teratogenic effects. In addition, there is no evidence that there is an associated increased pregnancy loss following use of etanercept [25]. In this study, higher pregnancy rates were determined in the control and etanercept groups than the LPS and etanercept + LPS groups (Table 1). The uses of anti-TNF- $\alpha$ agents decrease the proportion of fetal deaths in LPS-administered pregnant mice [11].

When TNF- $\alpha$ level increases during pregnancy, placental perfusion is inadequate, there is an increase in thrombotic events, and placental and fetal hypoxia occur [22]. In addition, a higher TNF- $\alpha$ level was measured in the etanercept + LPS group in the current study (Table 2). Cytokines play a pivotal role in the pregnancy process [26]. Spontaneous abortion, preterm labour, pre-eclampsia, and intrauterine growth restriction are adverse pregnancy outcomes in which deregulation of cytokine networks can result [4]. While the TNF- $\alpha$ level is low in the first trimester of pregnancy, the TNF- $\alpha$ level reaches a peak during the onset of labour [25].
Low-dose LPS and Th1 cytokines (TNF- $\alpha$ and IL-2) induce embryonic resorption without affecting mother survival, and the implantation site is extremely sensitive to these molecules during early pregnancy [1]. It has been reported that TNF- $\alpha$ production in fetal membranes is increased by LPS. TNF- $\alpha$ has an important role as a cytokine in pregnancy and leads to the induction of labour in synergy with other inflammatory cytokines, which cause uterine contractions [3,25]. TNF- $\alpha$ has an effect on blastocyst implantation, endometrial vascular permeability, and uterine deciduation. High serum and amniotic fluid levels of TNF- $\alpha$ determine fetal growth retardation and the onset of labour. It has been reported that recurrent pregnancy loss is closely linked to the LPS-increased TNF- $\alpha$ level. The mechanism underlying fetoplacental resorption caused by LPS may be based on haemorrhage, and necrosis results from a direct effect of TNF- $\alpha$ on the placental vasculature $[10,25]$.

In the current study, etanercept increased the concentration of TNF- $\alpha$ (14.5-fold) and the concentration of IL-10 (2.2-fold) when compared to the LPS group (Table 2). IL-10 has a protective role, while TNF- $\alpha$ is an abortive factor during pregnancy [5]. Thus, etanercept did not prevent pregnancy loss. This finding may have reflected an insufficient dose of etanercept. In addition, LPS-induced abortions are prevented by IL-10 injections or LPS-induced fetal death is decreased by IL-10 injections [22,23].

Adverse effects did not occur in the offspring of the etanercept or control groups, and there was no difference between the two groups statistically. It has been noted that TNF- $\alpha$ inhibitors are not associated with adverse pregnancy outcomes, including spontaneous abortion, stillbirth, low birth weight, and congenital malformations. Based on a study in which cynomolgus monkeys received TNF- $\alpha$ inhibitors several hundred times the recommended human dose, there was no evidence of teratogenic effects, and adverse pregnancy or maternal outcomes in embryo-fetal perinatal developmental toxicity studies [19].

The decreased pregnancy rate in the etanercept + LPS and LPS groups (Table 1) may reflect the inability of etanercept to sufficiently increase the level of IL10 , thus potentiating the effect of etanercept on TNFproduction. In conclusion, etanercept may not prevent infection- or endotoxemia-mediated pregnancy loss.

\section{CONCLUSION}

Etanercept does not pose a major teratogenic risk and has no preventive effects with respect to infection-dependent pregnancy loss. 
MANUFACTURERS

${ }^{1}$ Sigma-Aldrich Chemie. Deisenhofen, Germany.

${ }^{2}$ Wyeth. Istanbul, Turkey.

${ }^{3}$ Ulagay Ilac Sanayi. Istanbul, Turkey.

${ }^{4}$ eBioscience. San Diego, CA, USA.

${ }^{5}$ Bio-Tek Instruments. Winooski, VT, USA.
Ethical approval. The study protocol was approved by the Ethics Committee of Necmettin Erbakan University, Experimental Medicine, Research and Application Center, Konya, Turkey.

Declaration of interest. The authors report no conflicts of interest. The authors alone are responsible for the content and writing of the paper.

\section{REFERENCES}

1 Aisemberg J., Vercelli C., Wolfson M., Salazar AI., Osycka-Salut C., Billi S., Ribeiro M.L., Farina M. \& Franchi A.M. 2010. Inflammatory agents involved in septic miscarriage. Neuroimmunomodulation. 17(3): 150-152.

2 Anonymous. 2014. A complex process: How pregnancy occurs. Fertility.com (Online). Available at: http://www.fertility.com/en/stage1/articles/article4/article4.html . [Accessed in July 2015].

3 Calleja-Agius J., Muttukrishna S. \& Jauniaux E. 2012. The role of tumor necrosis factor-receptors in pregnancy with normal and adverse outcome. International Journal of Contemporary Medical Research. 4: 1-15.

4 Challis J.R., Lockwood C.J., Myatt L. \& Norman J.E. 2009. Strauss 3 rd J.F. \& Petraglia F. Inflammation and pregnancy. Reproductive Sciences. 16(2): 206-215.

5 Chaouat G., Zourbas S., Ostojic S., Lappree-Delage G., Dubanchet S., Ledee N. \& Martal J. 2002. A brief review of recent data on some cytokine expressions at the materno-foetal interface which might challenge the classical Th1/ Th2 dichotomy. Journal of Reproductive Immunology. 53(1-2): 241-256.

6 Christiansen O.B., Nielsen H.S. \& Kolte A.M. 2006. Inflammation and miscarriage. Seminars in Fetal and Neonatal Medicine. 11(5): 302-308.

7 Er A. 2013. Azithromycin prevents pregnancy loss: reducing the level of tumor necrosis factor-alpha and raising the level of interleukin-10 in rats. Mediators of Inflammation. Article id: 928137.

8 FDA. 2008. Etanercept. Available at: http://www.fda.gov/downloads/advisorycommittees/committeesmeetingmaterials/ pediatricadvisorycommittee/ucm191922.pdf . [Accessed in June 2015].

9 Friebe A. \& Arck P. 2008. Causes for spontaneous abortion: what the bugs 'gut' to do with it? The International Journal of Biochemistry \& Cell Biology. 40(11): 2348-2352.

10 Gendron R.L., Nestel F.P., Lapp W.S. \& Baines M.G. 1990. Lipopolysaccharide-induced fetal resorption in mice is associated with the intrauterine production of tumour necrosis factor-alpha. Journal of Reproduction and Fertility. 90(2): 395-402.

11 Holmgren C., Esplin M.S., Hamblin S., Molenda M., Simonsen S. \& Silver R. 2008. Evaluation of the use of antiTNF-alpha in an LPS-induced murine model. Journal of Reproductive Immunology. 78(2): 134-139.

12 Jauniaux E., Farquharson R.G., Christiansen O.B. \& Exalto N. 2006. Evidence-based guidelines for the investigation and medical treatment of recurrent miscarriage. Human Reproduction. 21(9): 2216-2222.

13 Karabacak A. \& Yazar E. 2006. Current approaches in the treatment of septic shock. Eurasian Journal of Veterinary Sciences. 22(1-2): 95-103.

14 Laird S.M., Tuckerman E.M., Cork B.A., Linjawi S., Blakemore A.I. \& Li T.C. 2003. A review of immune cells and molecules in women with recurrent miscarriage. Human Reproduction Update. 9(2): 163-174.

15 Marchioni R.M. \& Lichtenstein G.R. 2013. Tumor necrosis factor- $\alpha$ inhibitor therapy and fetal risk: a systematic literature review. World Journal of Gastroenterology. 19(17): 2591-2602.

16 Mitchell B.F. \& Taggart M.J. 2009. Are animal models relevant to key aspects of human parturition? American Journal of Physiology - Regulatory, Integrative and Comparative Physiology. 297(3): 525-545.

17 Murphy S.P. \& Sharma S. 2006. IL-10 and pregnancy. In: Mor G. (Ed). Immunology of Pregnancy. New York: Springer, pp.26-36.

18 Ní C.C., Keane J., Lavelle E.C., Hope J.C. \& Harris J. 2011. Autophagy in the immune response to tuberculosis: Clinical perspectives. Clinical \& Experimental Immunology. 164(3): 291-300.

19 Nielsen O.H., Loftus E.V. \& Jess T. 2013. Safety of TNF- $\alpha$ inhibitors during IBD pregnancy: a systematic review. BMC Medicine. 11(174): 1-13. 
20 Petroff M.G. 2011. Review: Fetal antigens-identity, origins, and influences on the maternal immune system. Placenta. 32(2): 176-181.

21 Pompili M., Biolato M., Miele L. \& Grieco A. 2013. Tumor necrosis factor- inhibitors and chronic hepatitis C: a comprehensive literature review. World Journal of Gastroenterology. 19(44): 7867-7873.

22 Renaud S.J., Cotechini T., Quirt J.S., Macdonald-Goodfellow S.K., Othman M. \& Graham C.H. 2011. Spontaneous pregnancy loss mediated by abnormal maternal inflammation in rats is linked to deficient uteroplacental perfusion. The Journal of Immunology. 186(3): 1799-1808.

23 Robertson S.A., Care A.S. \& Skinner R.J. 2007. Interleukin 10 regulates inflammatory cytokine synthesis to protect against lipopolysaccharide-induced abortion and fetal growth restriction in mice. Biology of Reproduction. 76(5): 738748.

24 Rothberg H. 1960. Effects of cytotoxic agents on the fetus. The Journal of the American Medical Association. 173(14): 1616.

25 Roux C.H., Brocq O., Breuil V., Albert C. \& Euller-Ziegler L. 2007. Pregnancy in rheumatology patients exposed to anti-tumour necrosis factor (TNF)-alpha therapy. Rheumatology (Oxford). 46(9): 695-698.

26 Saeed S.A., Qureshi Z., Saleem A., Quadri J., Sheikh A.F. \& Waqar M.A. 2008. Prostaglandins and Cytokines in Pregnancy and Labor. Journal of the Chemical Society of Pakistan. 30(6): 963-971.

27 Thellin O., Coumans B., Zorzi W., Igout A. \& Heinen E. 2000. Tolerance to the foeto-placental 'graft': ten ways to support a child for nine months. Current Opinion in Immunology. 12(6): 731-737.

28 Trowsdale J. \& Betz A.G. 2006. Mother's little helpers: mechanisms of maternal-fetal tolerance. Nature Immunology. 7(3): 241-246.

29 Zegers-Hochschild F., Adamson G.D., de Mouzon J., Ishihara O., Mansour R., Nygren K., Sullivan E. \& Vanderpoel S. 2009. The International Committee for Monitoring Assisted Reproductive Technology (ICMART) and the World Health Organization (WHO) Revised Glossary on ART Terminology. Human Reproduction. 24(11): 2683-2687. 